\title{
Cytomorphological study of lymph node lesions: a study of 250 cases
}

\author{
Patel A.S. ${ }^{1}$, Rathod G.B. ${ }^{2}$, Shah K.J. ${ }^{3}$ \\ ${ }^{1}$ Dr. Amita S. Patel, Assistant Professor, ${ }^{2}$ Dr. Gunvanti B. Rathod, Associate Professor, ${ }^{3}$ Dr. Kamlesh J. Shah, Professor \\ $\&$ head, all authors are affiliated with Pathology Department, GMERS Medical College, Halar Road, Valsad, Gujarat, \\ India.
}

Corresponding Author: Dr. Amita S. Patel, Assistant Professor, Pathology Department, GMERS Medical College, Halar Road, Valsad, Gujarat, India. E-mail id: amita1883@gmail.com

\begin{abstract}
Introduction: Lymph node enlargement is frequent presentation in all age groups with a wide spectrum of diseases, ranging from infections to malignancy. Therefore, management of cases depends on lymph node pathology, which can be studied by collecting material through fine needle aspiration method that can be used as an outpatient procedure. Objectives: The study was undertaken to assess the cytomorphological features and incidence of various lymph node diseases on fine-needle aspiration cytology (FNAC) and to analyze the utility and diagnostic importance of FNAC in lymph node diseases. Materials and Methods: In the study, total of 250 patients were selected who had presented with lymph node enlargement at Department of Pathology in our Tertiary Care Centre. Results: In this series of FNAC, cervical lymph nodes were involved in majority of $171(68.4 \%)$ cases. The age of patients ranged from 6 months to 92 years with slight male preponderance. Tubercular lymphadenitis comprised the majority (50.8\%) followed by reactive lymphoid lesions (20.8\%), metastatic malignancies and acute suppurative lymphadenitis (8.8\%) each, granulomatous lymphadenitis (8.4\%), chronic nonspecific lymphadenitis $(1.2 \%)$, necrotizing lymphadenitis $(0.8 \%)$ and lymphoma $(0.4 \%)$. Conclusion: FNAC is a simple, safe, reliable, inexpensive and the most diagnostic tool in early detection of lymph node lesions.
\end{abstract}

Keywords: Fine-needle aspiration cytology, Lymphadenitis, Tuberculosis

\section{Introduction}

Lymph nodes are most widely distributed, easily accessible and an integral component of the immune system. Their involvement is a common presentation and frequently examined for diagnostic purpose in the clinical practice [1].

The lymphoid system grows rapidly in childhood and reached its stable adult size till 20-25 years. Lymph nodes are pink gray bean shaped encapsulated organs which cluster along the lymphatic vessels of the body. There are hundreds of these small organs, but because they are usually embedded in connective tissue, they are not ordinarily seen. Infection and inflammatory stimuli elicit immune reaction within lymph nodes produce enlarged lymph nodes which are clinically palpable. The common sites of distribution are cervical, axillary, mediastinal, retroperitoneal, iliac, and inguinal regions.

The fine-needle aspiration cytology (FNAC) in lymph node was first used by Greig and Gray in 1904 to

Manuscript received: $8^{\text {th }}$ March 2019

Reviewed: $18^{\text {th }}$ March 2019

Author Corrected: $24^{\text {th }}$ March 2019

Accepted for Publication: $28^{\text {th }}$ March 2019 diagnosed trypanosomiasis and Guthrie in 1921 systemically performed FNA on lymph nodes for diagnostic purpose [2] Since then FNAC has been a simple, safe, rapid, reliable, and cost effective method of establishing the diagnosis of lesions and masses in various sites and organs and is the most convenient for outdoor as well as bedside indoor patients [3-7]. Also as a minimally invasive technique, it helps in early direction of appropriate investigations in conjunction with sophisticated CT, MRI and USG guided procedures.

The aim of this study is to highlight wonderful and diagnostic role of FNAC in different age group patients presenting with lymph node enlargement and to assess the cytomorphological features and incidence of various lymph node diseases on FNAC.

\section{Materials and Method}

This retrospective study was carried out in Department of pathology, GMERS medical college, Valsad which is a tertiary care centre to study the various cytomor- 
phological features of neoplastic and non-neoplastic lesions of lymph nodes by FNAC in patients presenting with lymphadenopathy and to determine the incidence of various lymph node diseases among them. This was a retrospective study conducted over a period of 1 year from January 2017 to December 2017, and a total of 250 cases of lymphadenopathy of varied etiologies were considered. All patients presenting with lymph node enlargement were included in the study. Study participants were subjected to standard FNA procedure after taking written consent from the patient or guardian (in case of paediatric patients). We have taken approval for research study from Human Ethical committee.

After taking a brief clinical history, meticulous physical examination was done and the findings were noted. FNAC was performed using 22-24 Gauge needles attached to $10 \mathrm{ml}$ syringes. Few passes were given with sufficient negative pressure then the needle was removed and the pressure was applied to the area of aspiration to avoid bleeding or hematoma formation.

The aspirated material was smeared onto glass slides. Smears were fixed in methanol and stained with Haematoxylin \& eosin stain and Papanicolaou stain. May Grunwald Giemsa (MGG) stain was done on air dried smears and examined under the microscope. Ziehl-Neelsen (ZN) staining was done whenever a cytological diagnosis of granulomatous disease was made and also in cases with abundant necrosis and

\section{Original Research Article}

suppuration. In cases where fluid was aspirated on FNAC, the fluid was centrifuged and smears were made from the sediment followed by the above staining methods.

Based on the cellularity, the smears were categorized as of high, moderate, and low cellularity.

Inclusion criteria: all theneoplastic and non-neoplastic lesions of lymph nodes by FNAC in patients presenting with lymphadenopathy

Exclusion criteria: The smears which were hemorrhagic, with scanty cellularity to the extent that diagnosis could not be offered were labeled as inadequate for opinion and they were excluded from study.

The cytological diagnosis for each case was based on cytomorphology and available clinical information. The diagnoses were categorized broadly as tuberculous lymphadenitis, reactive lymphadenitis, metastatic lymphadenopathy, acute suppurative lymphadenitis, chronic nonspecific lymphadenitis, necrotizing lymphadenitis and lymphoma. The tuberculous lymphadenitis cases were further divided into three groups on the basis of cytomorphological analysis: group 1 - epithelioid granulomas without necrosis, group 2 - caseating epithelioid granulomas and group 3 - necrosis without epithelioid granulomas.

\section{Results}

During this period, total of 250 aspirates were studied from the patients with lymphadenopathy, out of which 131 were males and 119 females. The age of the patients varied from 6 month to 92 years with a mean age of 29.9 years. The youngest patient had tuberculous lymphadenitis whereas the oldest patient had metastasis from squamous cell carcinoma. The maximum incidences of cases were seen in the age range of 20-29 years. A slight male preponderance was noted with a male to female ratio of 1.1:1. The female's preponderance was particularly very high in 3rd decade of life whereas it was male preponderance in the $4 \mathrm{rd}$ decade of life. In younger age group and in elderly population, there was no significant difference in the incidence of disease amongst males and females (Table 1).

Table-1: Age and sex wise distribution of cases.

\begin{tabular}{|c|c|c|c|c|}
\hline Age & No. of male cases & No. of female cases & Total & Percentage \\
\hline $0-9$ & 16 & 11 & 27 & 10.8 \\
\hline $10-19$ & 20 & 22 & 42 & 16.8 \\
\hline $20-29$ & 31 & 41 & 72 & 28.8 \\
\hline $30-39$ & 22 & 21 & 43 & 17.2 \\
\hline $40-49$ & 28 & 13 & 41 & 16.4 \\
\hline $50-59$ & 6 & 4 & 10 & 4 \\
\hline $60-69$ & 5 & 5 & 10 & 4 \\
\hline$\geq 70$ & 4 & 1 & 5 & 2 \\
\hline
\end{tabular}

Lymph nodes of varying sizes were noticed on palpation for FNAC. The smallest lymph node measured $0.5 \mathrm{~cm}$ and the largest measured $10 \mathrm{~cm}$ in maximum dimensions. Most of the lymph nodes (183 cases, 73.2\%) ranged in size between 1 


\section{Original Research Article}

and $2 \mathrm{~cm}, 8$ cases $(3.2 \%)$ were $<1 \mathrm{~cm}$ and 59 cases $(23.6 \%)$ were $>2 \mathrm{~cm}$ in size. In 167 cases single lymph node was involved, two lymph nodes were involved in 2 cases and more than 2 lymph nodes were found in 81 cases. The lymph nodes in tuberculosis were multiple, soft to firm, tender and matted; while they were discrete in reactive lymphadenitis and firm to hard, non-tender and fixed in majority of metastatic lesions.

The most common group of lymph nodes aspirated were cervical (68.4\%), submandibular (10.8\%), supraclavicular $(10 \%)$, axillary $(5.2 \%)$, submental $(3.6 \%)$, inguinal $(1.2 \%)$ and generalized which were $(0.8 \%)$ in the study. Cervical lymph node showed bilateral involvement in 20 cases, otherwise no significant difference was found in laterality of involvement. (Table 2) Cervical group of lymph node includes anterior, lateral and posterior cervical lymph nodes.

Table-2: Site and side of lymph node group involved in various lymph node lesions.

\begin{tabular}{|c|c|c|c|c|c|c|}
\hline Sr. No. & Site & Right & Left & Bilateral & Total & Percentage \\
\hline 1 & Cervical & 76 & 75 & 20 & 171 & 68.4 \\
\hline 2 & Submandibular & 15 & 12 & - & 27 & 10.8 \\
\hline 3 & Supraclavicular & 14 & 11 & - & 25 & 10 \\
\hline 4 & Axillary & 8 & 5 & - & 13 & 5.2 \\
\hline 5 & Submental & - & - & - & 9 & 3.6 \\
\hline 6 & Inguinal & 2 & 1 & - & 3 & 1.2 \\
\hline 7 & Generalized $^{*}$ & 2 & - & - & 2 & 0.8 \\
\hline & Total & $\mathbf{1 1 7}$ & $\mathbf{1 0 4}$ & $\mathbf{2 0}$ & $\mathbf{2 5 0}$ & $\mathbf{1 0 0}$ \\
\hline
\end{tabular}

* Involvement of two or more groups of lymph nodes was considered to be generalized

The most common cytological diagnosis made was tuberculous lymphadenitis in 127 cases (50.8\%) followed by reactive lymphadenitis 52 cases (20.8), 22 cases of metastatic malignancy and acute suppurative lymphadenitis each i.e., 8.8\%, granulomatous lymphadenitis 21 cases $(8.4 \%), 3$ cases of chronic nonspecific lymphadenitis $(1.2 \%), 2$ cases of necrotizing lymphadenitis and a single case of non-Hodgkin's lymphoma (Table 3 )

Table-3: Cytomorphological diagnosis of aspirated lesion.

\begin{tabular}{|c|c|c|c|}
\hline Sr. No. & Cytomorphological Diagnosis & No. of Cases & Percentage \\
\hline 1 & Tuberculous lymphadenitis & 127 & 50.8 \\
\hline 2 & Reactive Lymphadenitis & 52 & 20.8 \\
\hline 3 & Metastatic lymphadenitis & 22 & 8.8 \\
\hline 4 & Acute suppurative lymphadenitis & 21 & 8.8 \\
\hline 5 & Granulomatous lymphadenitis & 3 & 1.2 \\
\hline 6 & Chronic non specific lymphadenitis & 2 & 0.8 \\
\hline 7 & Necrotizing lymphadenitis & 1 & 0.4 \\
\hline 8 & Non-Hodgkin lymphoma & $\mathbf{2 5 0}$ & $\mathbf{1 0 0}$ \\
\hline
\end{tabular}

Table-4: Cytomorphological findings of tuberculous lymphadenitis.

\begin{tabular}{|c|c|c|}
\hline Cytomorphological findings & No. of cases (\%) & AFB* positivity \\
\hline Epithelioid granulomas without necrosis & $24(18.9)$ & 1 \\
\hline Caseating epithelioid granulomas & $59(46.5)$ & 32 \\
\hline Necrosis without epithelioid granulomas & $44(34.6)$ & $\mathbf{4 5}$ \\
\hline Total & $\mathbf{1 2 7 ( 3 5 . 4 )}$ & 12 \\
\hline
\end{tabular}

AFB: Acid fast bacilli

The majority of cases recorded were those of tuberculous lymphadenitis 127 (50.8\%) cases [Figure 1] in which $66.1 \%$ were from the cervical group of lymph nodes. The tuberculous lymphadenitis cases were further divided into three groups 


\section{Original Research Article}

on the basis of cytomorphological analysis; group1: epithelioid granulomas without necrosis - 24/127 (18.9\%), group 2: caseating epithelioid granulomas - 59/127 (54.5\%) and group 3: necrosis without epithelioid granulomas - 44/127 (34.6\%). Acid fast bacilli positivity on ZN staining was seen in 45 out of 127 cases (35.4\%) [Figure 2] of tuberculous lymphadenitis. (Table 4) In present study out of 127 cases, 7 cases (5.5\%) had positive family history with known cases of tuberculosis in family members and 14 cases $(11 \%)$ had past history of tuberculosis and taken anti tubercular treatment for 6 months before 6 months to 17 years back. There were 4 cases (3\%) had HIV infection.

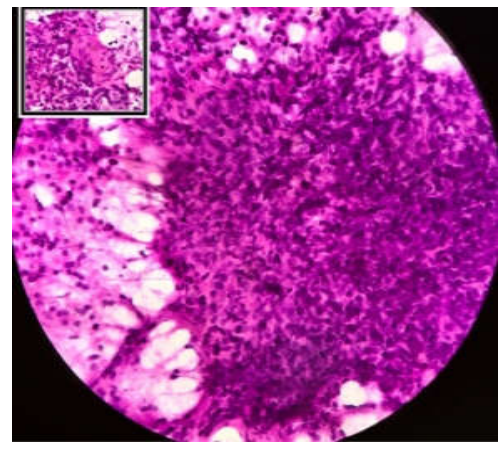

Fig-1

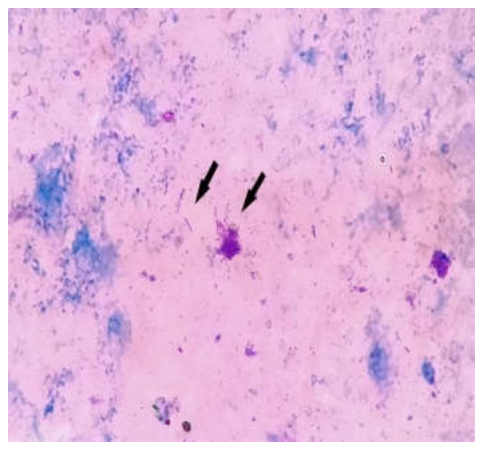

Fig-2

Figure-1: Aspirates from tuberculous lymphadenitis show well-formed granulomas and inset shows giant cell with epithelioid cells (H\&E, 40X).

Figure-2: Smear showing acid fast bacilli (arrows) in a background of necrosis (ZN staining, 100x)

Next frequent diagnosis was reactive lymphadenitis with 52 (20.8\%) cases [Figure 3] In majority of cases (46/52 cases), the size of lymph node was $\leq 2 \mathrm{~cm}$ in diameter.

A total of $22(8.8 \%)$ cases were diagnosed as metastatic deposits in the study mainly from oral cavity. A marked male preponderance was noted with a maximum number of cases recorded in the cervical group of lymph nodes followed by submandibular lymph node. Lymph node size was $\geq 3 \mathrm{~cm}$ in $17 / 22(77.27 \%)$ cases.

Maximum cases of metastatic deposits in the study were those of squamous cell carcinoma (18 cases, 82\%) [Figure 4], followed by poorly differentiated carcinoma, adenocarcinoma [Figure 5], infiltrating ductal carcinoma of breast and papillary carcinoma of kidney ( 1 case, $4.5 \%)$ each. Out of 22 cases, 6 cases $(27.2 \%)$ had history of tobacco chewing since 5 to 45 years.

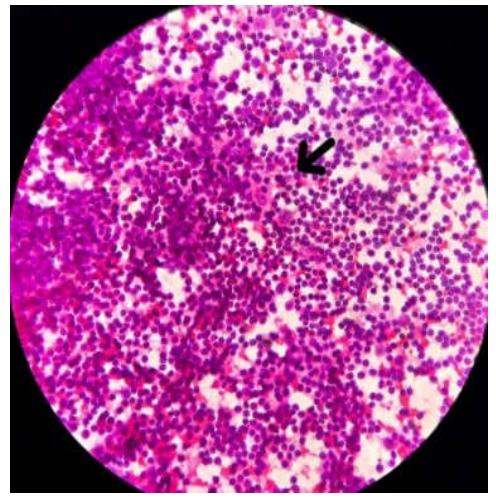

Fig-3

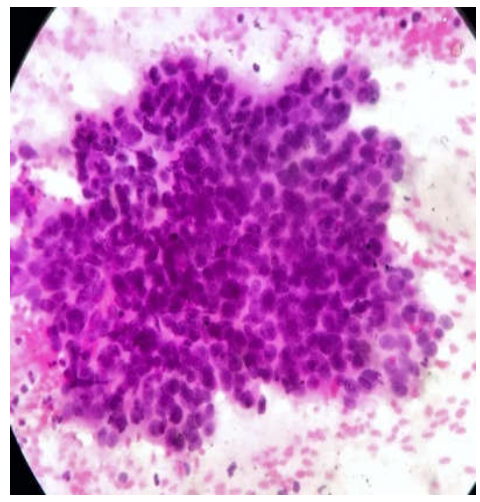

Fig-4

Figure-3: Aspirates from reactive lymphadenitis, showing polymorphous population of lymphoid cells and a tingible body macrophage (arrow) (H \& E, 40x).

Figure-4: Aspirates from metastatic squamous cell carcinoma - A cluster of neoplastic squamous cells with highly pleomorphic cells having ample basophilic cytoplasm (H \& E, 40x) 


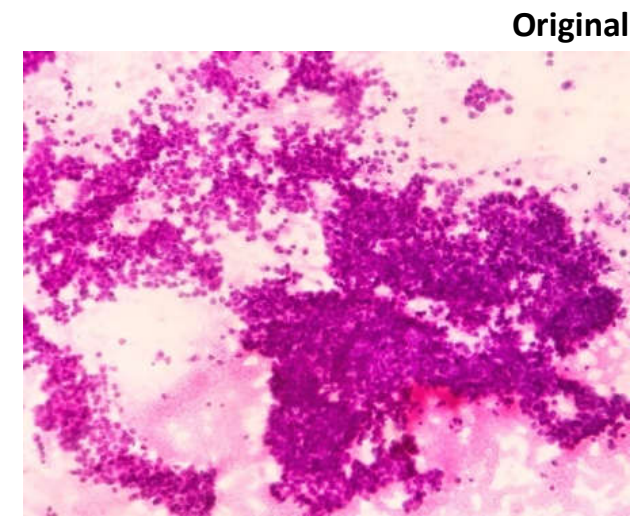

Figure-5: Aspirates from metastatic adenocarcinoma- Neoplastic cells with delicate cytoplasm and pleomorphic, hyperchromatic nucleus arranged in cell clusters and glandular pattern (H\&E, 40x)

A total of 12 cases $(6.41 \%)$ of acute suppurative lymphadenitis have been recorded in this study with maximum of them in the cervical group of lymph nodes. Granulomatous Lymphadenitis was observed with 21 cases $(8.4 \%)$ in our study.

The present study also comprised $3(1.2 \%)$ cases diagnosed as chronic non Specific Lymphadenitis and $2(0.8 \%)$ cases of necrotizing lymphadenitis. There was a $1(0.4 \%)$ case of Non Hodgkin's lymphoma.

\section{Discussion}

Inflammatory processes whether it is symptomatic or asymptomatic are the most common causes of peripheral lymphadenopathy and it is of great clinical significance as underlying disease may range from treatable infectious etiology to malignant neoplasm and requires accurate diagnosis so that proper treatment guideline can be started as soon as possible. Although the surgical excision of a peripheral lymph node is relatively simple, but the drawback is that procedure does require anesthesia, hospitalization, time consuming and the patient may get a scar for lifetime.

While on the other hand, FNAC is a simple, safe, reliable, quick, inexpensive and important diagnostic tool of establishing the diagnosis of lesions and masses in various sites and organs [3-9] Enlarged lymph nodes were the first organs to be sampled by FNAC [10] However, this procedure has limitations and pitfalls.

In the present study, we made an attempt to present our experience with 250 FNAC cases of palpable lymph node swellings and diagnosis based on the cytomorphological spectrum of lymph node lesions.

In this study, maximum number of cases recorded in age group of 20-29 years and slight male preponderance with male: female ratio of 1.1:1. This is in accordance with various other studies with similar findings $[3,5,9,11,13-20]$. While, the study done by Sharma et al [12], Sharma et al [21] and Duraiswami et al [22] showed that females were affected more commonly than males with male: female ratio of $1: 1.13,0.87: 1$ and $1: 1.6$ respectively. The male predominance could be accounted for more susceptibility of males due to high outdoor activities compared to females. In our study, the youngest patient was 6 months old and oldest was 92 years of age. These figures come in close comparison to other studies $[3,15,19]$.

Tuberculous lymphadenitis was most often (55.1\%) seen in the third and fourth decades, while 53.8\% of reactive lymphadenitis cases were seen in first two decades of life. Reactive lymphadenitis due to underlying acute bacterial or viral infection was the commonest cause of significant lymphadenopathy in children. All the neoplastic lesions were seen above 40 years of age (100\%). Males showed preponderance of tuberculous lymphadenitis, lymphoma and metastatic lymphadenitis, while reactive hyperplasia showed a slight female preponderance. The study done by Shilpa et al [15] and Kochhar et al [20] also found the highest incidence of tuberculous lymphadenitis was seen in second and third decades with female preponderance and decreasing incidence with age.

The present study showed significant correlation with size of lymph node involved as out of 52 cases of reactive lymphadenitis, 46 cases $(88.5 \%)$ had $\leq 2 \mathrm{~cm}$ sized lymph nodes and out of 22 cases of metastatic lymphadenitis, 17 cases (77.3\%) had $\geq 3 \mathrm{~cm}$ sized lymph nodes. The study conducted by Reddy et al [23] found significant correlation with various site and diagnosis where as a study done by Vimal et al [9] found no correlation based on size of lymph node. 


\section{Original Research Article}

Cervical lymph nodes were the most common group of lymph nodes involved $(68.4 \%)$. Similar findings were also observed by other authors $[3,7,9,12,18,19]$.

In this study, we observed non-neoplastic lesions like tuberculous lymphadenitis, reactive lymphadenitis, acute suppurative lymphadenitis, granulomatous lymphadenitis, chronic non specific lymphadenitis and necrotizing lymphadenitis to neoplastic lesions like metastatic lymphadenitis and non Hodgkin's lymphoma which were in accordance with majority of studies (Table 5)

Table-5: Comparison of the present study with the other studies.

\begin{tabular}{|c|c|c|c|c|c|c|c|c|c|c|c|c|}
\hline \multirow{2}{*}{$\begin{array}{l}\text { Sr. } \\
\text { no }\end{array}$} & \multirow{2}{*}{$\begin{array}{c}\text { Name of } \\
\text { authors }\end{array}$} & \multirow{2}{*}{$\begin{array}{l}\text { Total } \\
\text { no. of } \\
\text { cases }\end{array}$} & \multicolumn{6}{|c|}{ Non neoplastic lesions (\%) } & \multicolumn{3}{|c|}{ Neoplastic lesions (\%) } & \multirow{2}{*}{$\begin{array}{l}\text { Other } \\
(\%)\end{array}$} \\
\hline & & & TB LN & $\begin{array}{l}\text { Rea } \\
\text { LN }\end{array}$ & $\begin{array}{c}\text { Ac } S \\
\text { LN }\end{array}$ & $\begin{array}{l}\text { Gra } \\
\text { LN }\end{array}$ & $\begin{array}{c}\text { Ch NS } \\
\text { LN }\end{array}$ & $\begin{array}{l}\text { Nec } \\
\text { LN }\end{array}$ & $\begin{array}{l}\text { Met } \\
\text { LN }\end{array}$ & NHL & HL & \\
\hline 1 & $\begin{array}{l}\text { Gayathri } \\
\text { et al (3) }\end{array}$ & 1774 & 14.65 & 26.22 & 3.94 & 14.7 & 18.5 & - & 21.2 & 0.56 & 0.17 & - \\
\hline 2 & $\begin{array}{l}\text { Mohanty } \\
\text { et al (7) }\end{array}$ & 355 & 7.88 & 34.36 & 11.26 & 20.28 & 2.81 & - & 18.30 & 3.66 & 0.28 & 1.12 \\
\hline 3 & $\begin{array}{c}\text { Khajuria } \\
\text { et al (8) }\end{array}$ & 656 & 52.3 & 37.2 & 1.0 & - & - & - & 3.8 & 1.2 & 0.8 & 0.15 \\
\hline 4 & $\begin{array}{l}\text { Patel et } \\
\text { al (11) }\end{array}$ & 580 & 50.52 & 14.66 & 5 & - & - & - & 27.06 & 2.07 & 0.69 & - \\
\hline 5 & $\begin{array}{c}\text { Sharma } \\
\text { et al (12) }\end{array}$ & 268 & 54.5 & 7.8 & 21 & 16.8 & - & - & 10.4 & 1.5 & 0.8 & 0.4 \\
\hline 6 & $\begin{array}{l}\text { Shah et } \\
\text { al (13) }\end{array}$ & 555 & 44.8 & 16.7 & 5.4 & - & - & - & 31.3 & 0.9 & 0.9 & - \\
\hline 7 & $\begin{array}{c}\text { Patil et al } \\
\text { (14) }\end{array}$ & 1478 & 40.06 & 37.2 & 4.2 & - & - & - & 16.4 & 1.6 & 0.4 & 2 \\
\hline 8 & $\begin{array}{c}\text { Shilpa et } \\
\text { al (15) }\end{array}$ & 943 & 48.5 & 27.4 & 6.9 & - & - & - & 23.9 & 1.7 & 0.2 & 0.2 \\
\hline 9 & $\begin{array}{l}\text { Nikethan } \\
\text { et al (18) }\end{array}$ & 322 & 45.34 & 18.01 & 3.12 & 13.97 & 3.72 & - & 13.35 & 0.6 & 1.2 & - \\
\hline 10 & $\begin{array}{l}\text { Sharma } \\
\text { et al (21) }\end{array}$ & 736 & 56.93 & 26.22 & 6.11 & - & - & - & 6.38 & 2.31 & 0.4 & 0.28 \\
\hline 11 & $\begin{array}{c}\text { Present } \\
\text { study }\end{array}$ & 250 & 50.8 & 20.8 & 8.8 & 8.4 & 1.2 & 0.8 & 8.8 & 0.4 & 0 & - \\
\hline
\end{tabular}

Tuberculous lymphadenitis was the most common lesion and was reported in 127/250 cases (50.8\%) which was correlated with the other studies [11-15,18,21,23]. The high rate is due to low socioeconomic status, illiteracy, incomplete treatment and resistance to the treatment. However some studies showed reactive hyperplasia as a most common finding $[3,5,7]$. This difference may be due to different study population and socio-economic condition of the patients. In our study TB lymphadenitis cases were associated with systemic symptoms i.e. fever, cough, fatigue, weight loss and anorexia. Our study had 14 cases that had completed their anti tubercular treatment but had persisting nodes or new emerging nodes which were in accordance with the study done by chand et al [24]. As in present study, tuberculous lymphadenitis was found in all age groups, results in the continuous transmission of the disease in the population. Hence, the diagnosis of this helps in preventing and treating the disease.

The cytomorphological pattern in tuberculosis is varied and divided into three patterns (Table 4). First was epithelioid granulomas without necrosis (18.9\%) in present study followed by caseatingepithelioid cell granulomas (46.5\%) and AFB positivity was maximum with necrosis without epithelioid granulomas pattern $(34.5 \%)$ which correlated with findings of other authors $[9,15,18]$.

In the current study, second most common cases recorded were those of reactive hyperplasia 52/250 cases (20.8\%). Reactive hyperplasia is a common form of lymphadenitis due to a variety of causes ranging from bacterial, viral, fungal or nonspecific etiology. These findings were in accordance with other studies [11-15,18,21,23] however some studies found metastatic lymphadenitis as a second most common cytological diagnosis $[11,13]$. It was may be due to different study population, genetic factors, environmental factors and habitual factors like smoking and tobacco consumption. 


\section{Original Research Article}

Metastatic lymphadenitis was observed in $22 / 250(8.8 \%)$ cases in our study which is comparable with the study done by other workers, Sharma et al [12] and Sharma et al [21]. In our study the cervical group was the most common to be involved by metastasis (15/22 cases, $68.1 \%)$ and the primary was most often from the oral cavity, which was similar findings observed by Hirachand et al [6] and Singh et al [17]. Males outnumbered females in these cases (M: F= 6.3: 1). Maximum cases were seen in age groups 40-69 years with squamous cell carcinoma being the most common histological type (81.8\% of all metastatic lymph nodes) which was similar to the study by Singh et al [17] and Kochhar et al [20] observed $75 \%$ and $83.78 \%$ respectively. However some study showed high rate of metastatic lymphadenitis $[11,13,15,20]$. The reason for higher metastasis is the regional variation and different study population. Rates for oral cavity, pharynx, oesophagus and larynx are highest in India, probably due to the habit of using multiple tobacco products [19]. Acute suppurative lymphadenopathy was observed in 22/250 (8.8\%) cases which is comparable with the study done by other workers ranged from $1 \%$ to $11.26 \%$ (Table 5 ).

The other frequent diagnosis in this study was observed to be granulomatous inflammation with $21 / 250$ cases (8.4\%). The incidence of granulomatous inflammation was observed to vary from $13.97 \%$ to $20.28 \%$ in other studies. (Table 5) Granulomas has variety of differential diagnosis causing lymphadenopathy other than tuberculosis including sarcoidosis, carcinoma, lymphoma, fungal diseases, cat scratch disease, collagen vascular disease and disease of the reticuloendothelial system [25]. The present study also comprised $3 / 250(1.2 \%)$ cases diagnosed as chronic nonspecific lymphadenopathy on cytology. This correlated with the study of Mohanty et al [7] and Nikethan et al [18] who found the incidence to be $2.81 \%$ and $3.72 \%$ of all lymph nodes aspirated respectively. However, Gayathri et al [3] observed $18.5 \%$ cases chronic nonspecific lymphadenitis. Other pathology in our series was necrotic lymphadenitis which was found in $2 / 250(0.8 \%)$ cases in accordance with $1.1 \%$ observed by Duraiswami et al [22]. Other cytological diagnosis in the present study was Non Hodgkin's lymphoma which was found in $1(0.4 \%)$ aspirates comparable with the study done by other workers ranged from $0.56 \%$ to $3.66 \%$. (Table 5) With the help of specialized investigation like flow cytometry and immunohistochemistry in adjunct to FNAC the diagnosis of NHL can be made much easier.

\section{Conclusion}

In conjunction with clinical picture of the patients, the accessibility of the enlarged lymph nodes for palpation and puncture, the rich cellularity of the smear due to the high yield of the aspirated material with proper technique and the ease with which the all variety of diagnosis with the hallmark features can be differentiated from lymphocytes makes the technique of FNA very useful in investigation of lymphadenopathy. FNAC has been yet again proved as an inexpensive, reliable and accurate diagnostic tool for the clinical set up in developing countries for the first line of investigation for lymphadenopathy. It helps in diagnosing metastatic diseases and gives the clue regarding the origin of the primary tumor which can be confirmed by advanced technique like immunohistochemistry on FNAC smear.

\section{Abbreviations}

TB LN-Tuberculous lymphadenitis

Rea LN- Reactive lymphadenitis

Ac S LN- Acute suppurative lymphadenitis

Gra LN- Granulomatous lymphadenitis

Ch NS LN- Chronic non-specific lymphadenitis

Nec LN- Necrotizing lymphadenitis

Met LN- Metastatic lymphadenitis

NHL- Non Hodgkin's lymphoma

HL- Hodgkin's lymphoma

Funding: Nil; Conflict of Interest: None initiated Permission from IRB: Yes

\section{References}

1. Kumar V, Abbas AK, Fausto N, Aster JC. Robbins Pathologic basis of disease. 8th ed. India: Elsevier; 2010. p.595.

2. Bibbo M. Lymph Nodes: Comprehensive Cytopathology. 2nd ed. USA: W.B.Saunders Company; 1996. p. 703-29.

3. Gayathri MN, Chaurasia S, Bharathi M, Shashidhar HB. Pattern of lymphadenopathy in fine needle aspiration cytology: a retrospective study. Int J Res Med Sci.2015 Jun;3(6):1416-9.

4. Meena A, Singh GP. Cytopathological study of tubercular lymphadenopathy on FNAC: analysis of 155 consecutive cases. Ind J of research. 2018 Jul;7(7):9-11.

5. Chawla N, Kishore S, Kudesia S: FNAC of Lymph Node Disorders. Indian Medical Gazette. 2012; 312-15.

6. Hirachand S, Lakhey M, Akhter J, et al. Evaluation of fine needle aspiration cytology of lymph nodes in Kathmandu Medical College, Teaching hospital. Kathmandu Univ Med J (KUMJ). 2009 Apr-Jun;7(26): 139-42.

7. Mohanty R, Wilkinson A. Utility of fine needle aspiration of lymph nodes. IOSR J Dent Med Sci. 2013 Jul-Aug;8(5):13-8. 
8. Khajuria R, Goswami KC, Singh K, Dubey VK. Pattern of lymphadenopathy on fine needle aspiration cytology in Jammu. JK Sci. 2006 Jul-Sep;8(3):157-9.

9. Vimal S, Dharwadkar A, Chandanwale SS, Vishwanathan V, Kumar H. Cytomorphological study of lymph node lesions: A study of 187 cases. Med J D Y Patil Univ. 2016 Jan-Feb;9(1):43-50.

10. Skoog L, Lowhagen J, Tani C: Lymph nodes. In: Gray W, Mckee G T, editors.Diagnostic Cytopathology. Churchill Livingstone; 1995. p. 481-513.

11. Patel MM, Italiya SL, Patel RD, Dudhat RB, Kaptan KR, Baldwa VM. Role of Fine Needle Aspiration Cytology to Analyze Various Causes of Lymphadenopathy. Natl J Community Med. 2013;4(3):489-92.

12. Sharma RI, Dharaiya CM. Study of fine needle aspiration cytology of lymphadenopathy in tertiary care centre of Ahmedabad, Gujarat.Trop J Path Micro. 2018; 4 (3):258-264. doi:10. 17511/jopm.2018.i3.04.

13. Shah PC, Patel CB, Bhagat V, Modi H. Evaluation of peripheral lymphadenopathy by fine needle aspiration cytology: a one year study at tertiary centre. Int J Res Med Sci. 2016 Jan;4(1):120-125.

14. Patil RK, Anubrolu IP, Kittur SK, Haravi RM, Aruna S, Jadhav MN. Cytological spectrum of lymph node lesionsour institute experience. Trop J Path Micro. 2017 Jul-Sep;3(3):354-361.

15. Shilpa G, Nataraju G. Pattern of Lymph Node Diseases in a Tertiary Level Referral Center: a cytological study of 943 cases. International Journal of Biological and Medical Research. 2013;4(3):3448-52.

16. Madan M, Kaur P, Manjari M, Sharma M. FNAC as a Diagnostic Tool in the Evaluation of Lymphadenopathy-A Tertiary Hospital Experience. Global Journal of Medical Research 2014;14(7):43-47.

17. Singh A, Bhambani P, Nema SK. Diagnostic accuracy of FNAC in diagnosis for causes of lymphade-

\section{Original Research Article}

nopathy: a hospital based analysis. Int J Res Med Sci 2013 Aug;1(3):271-7.

18. Nikethan B, Neethu GV, Hiremath SS, Patil SB. Role of fine needle aspiration cytology in the evaluation of the etiology of lymphadenopathy. Indian Journal of Pathology and Oncology 2016 Oct-Nov;3(4):548-551.

19. Shrivastav A, Shah HA, Agarwal NM, Santwani PM, Srivastava G. Evaluation of peripheral lymphadenopathy by fine needle aspiration cytology: A three year study at tertiary center. JNTR Univ Health Sci 2014;3 (2): 86-91.

20. A Kochhar, G Duggal, K Singh, S Kochhar. Spectrum Of Cytological Findings In Patients With Lymphadenopathy In Rural Population Of Southern Haryana, India - Experience In A Tertiary Care Hospital. The Internet Journal of Pathology. 2012; 13 (2) : 1-6

21. Sharma P, Rana S, Gill MK, Singh P, Satarkar RN, Kalhan S. Spectrum of lymph node lesions on cytology in rural Haryana: a retrospective analysis. Int J Res Med Sci 2015 May;3(5):1125-30.

22. Duraiswami R, Margam S, Chandran P, Prakash A. Spectrum of pathologies on FNAC evaluation of peripheral lymph nodes at a tertiary care center in hyderabad: a retrospective study. Int J Adv Med 2017 Feb; 4(1): 27-33.

23. Reddy MP, Moorchung N, Chaudhary A. Clinicopathological profile of pediatric lymphadenopathy. Indian J Pediatr. 2002 Dec;69(12):1047-51.

24. Chand P, Dogra R, Chauhan N, et al. Cytopathological Pattern of Tubercular Lymphade-nopathy on FNAC: Analysis of 550 Consecutive Cases. J Clin Diagn Res. 2014 Sep;8(9):FC16-9. doi: 10.7860/ JCDR/ 2014/9956.4910. Epub 2014 Sep 20.

25. Orell SR, Sterrett GF, Whitaker D. Lymph Nodes, Fine Needle Aspiration Cytology. 4th ed. India: Churchill Livingstone, Elsevier; 1999. p. 83-124.

\section{How to cite this article?}

Patel A.S, Rathod G.B, Shah K.J. Cytomorphological study of lymph node lesions: a study of 250 cases. Trop J Path Micro 2019;5(3):163-170.doi:10.17511/jopm.2019.i03.09. 